\title{
Students' Behavioral Intention to Use Learning Management System: The Mediating Role of Perceived Usefulness and Ease of Use
}

\author{
Albert Andry E. Panergayo and John Vincent C. Aliazas
}

\begin{abstract}
This paper investigates the mediating role of perceived usefulness and perceived ease of use on the effect of online learning self-efficacy factors: learning in an online environment, time management, and technology use to the students' behavioral intention to use learning management system. A cross-sectional explanatory research design was employed to collect and interpret the data gathered from 470 senior high students. Mediation analyses were initiated using PROCESS v3.5 following the procedure of Hayes (2013). Findings revealed that the three online learning self-efficacy factors, perceived usefulness, and perceived ease of use could explain the variation of students' behavioral intention to use. The results further showed that perceived usefulness and ease of use are both significant mediators in the relationship between online learning self-efficacy factors and student's behavioral intention to use. These results suggest that the future intention to use is higher when the students' perception of LMS found it valuable and easy to use. Development and adoption of LMS in educational institutions should consider the usefulness and manageability features to increase usage, fostering successful LMS-based course implementation.
\end{abstract}

Index Terms-Behavioral intention to use, mediating role, online learning self-efficacy, perceived ease of use, perceived usefulness.

\section{INTRODUCTION}

The educational transition from a conventional learning set-up to a flexible learning setting powered by the digital revolution has paved the way for utilizing the learning management system (LMS) [1]. Implementing LMS-based courses in conjunction with educational technology integration has promised a better quality and more student-centered education that promotes independent and active learning [2]. LMS is a web-based platform that enables educational institutions to provide the learners with lesson content and educational resources flexibly. It is an effective and responsive way for teachers to create, deliver, and manage their content and monitor participation and assess performance among learners [3]. LMS comes in various names such as course management system, learning content management system, virtual learning environment, and virtual learning system. LMS supports the teaching and

\footnotetext{
Manuscript received April 1, 2021; revised June 23, 2021. This work was supported in part by the Laguna State Polytechnic University in an effort to establish evidence of students' perception for future implementation learning management system-based courses in the university.

The authors are with College of Teacher Education and Senior High School Department, Laguna State Polytechnic University, San Pablo City, Laguna 4000, Philippines (e-mail: albertandry.panergayo@1spu.edu.ph, johnvincent.aliazas@1spu.edu.ph).
}

learning process in an online learning environment [4], [5]. It serves as a driving force in online learning schemes, which has become commonplace for nearly all higher education institutions and selected basic education schools [6] It is further composed of various features that permit faculty members to share educational materials and interact with their students in synchronous and asynchronous modalities [7], [8].

LMS should provide meaningful and authentic educational experiences for both teachers and learners. It needs to develop frequently, support differentiated activities such as teacher-student interaction, to provide interactive video tutorials and computer-assisted assessment [9]. Chaw and Tang [10] argued that LMS access does not guarantee effective learning despite its apparent usefulness. It is still an interesting question whether LMS indeed helps teachers promote practical understanding. Excluding information quality, the study further revealed that system quality and service quality are significantly associated with system use.

In contrast, system use had a significant relationship with learning effectiveness. Students' acceptance of the LMS is crucial to its effective application [11], [12]. Student's acceptance is configured by the user's attitude that translates to their behavioral intention to use - this explains the actual use of the system [13]. Dulkaman and Ali [14] contended that teachers should motivate the students to reinforce the use of LMS. In essence, students' perception and acceptance of LMS indicated by their intention to use are imperative to the successful application of LMS.

The adoption of LMS has focused on the pre-adoption stage [15], [16]. However, provided with the benefits of continuous utilization of the LMS, this study highlights the post-adoption of the LMS in the university, particularly at the senior high school level. Likewise, recent researches in LMS adoption are primarily situated in the context of higher education (i.e., [11], [15], [17]-[20]), and little is conducted at the secondary education level. The students' behavioral intention to use LMS is central to this study. Therefore, the purpose of this research is to examine the factors that influence the senior high school students' intention and continue to use LMS based on the framework of the Technology Acceptance Model [21]. It also seeks to confirm the mediating role of perceived usefulness (PU) and perceived ease of use (PEOU) between online learning self-efficacy as external factors and intention to use LMS.

\section{THEORETICAL FRAMEWORK}


Implementation of an innovation or new technology has been a trend in recent years. LMS, as such, requires acceptance from the users like the teachers and the students. The key to increasing the use of information technology systems is to increase its acceptance, which could be determined by asking individual users their future intention to use the technology [22]. Initially introduced by Fred Davis (1989), Technology Acceptance Model (TAM) is one of the famous research models that predicts the use and acceptance of information systems and technology by individual users [23], [24]. TAM's essential notion is that the users' behavioral intention determines their acceptance of the technology, which is established by their PU and PEOU [25]. TAM has been a widely used model to explain the users' behavior relevant to using an information system or a technology. Many types of research have been used to test the model, and results have been reliable [23]. This study has also led to numerous modifications in the proposed TAM initially. Further, Benbasat \& Barki [26] stated that emerging technologies have also caused significant changes in the model. These various modifications explain why the research community unanimously accepts no single model [27].

The original TAM recognizes Perceived usefulness (PU) and perceived ease of use (PEOU) are two fundamental determinants of user acceptance [21]. These two variables are central to TAM since it explains the actual system use. Davis (1989) defined PU as "the degree to which a person believes that using a particular system would enhance his or her job performance, p. 320." It explains the user's subjective probability that using a specific application system will improve their activity. On the other hand, Davis (1989) defined PEOU as "the degree to which a person believes that using a particular system would be free of effort, p. 320." This variable explains the expectations of users using a specific technology system as effortless. These two particular beliefs directly affect the attitudes towards use, influencing the behavioral intention to use (BIU). The basic TAM suggests that BIU predicts the actual usage of the system. Also, PEOU has been shown to significantly affect the PU, while PU has a direct effect on BIU.

Research in technology acceptance in teaching and learning has become an attractive trend due to the digitalization era. Consequently, TAM has been widely used in education to assist educators and policymakers in integrating information communication technology into teaching and learning. This model and its many versions have been used as a credible and leading scientific paradigm to assess diverse learning technologies [28]. For instance, Shroff, Deneen, and Ng [29] analyzed the TAM to determine the students' behavioral intention to use the e-portfolio system. It suggested that the TAM is a solid theoretical model where its validity can extend to an e-portfolio context.

On the other hand, Iqbal and Bhatti [20] investigated the role of students' readiness towards mobile learning using TAM as a paradigm. It contended that TAM has robust and parsimonious nature that made it an appropriate model for their study. Al-Maroof and Al-Meran [15] examine the factors affecting Google classroom acceptance among the undergraduates' students at one university based on the TAM. Fathema et al. [17] provided an empirical assessment of
TAM's extension [21] to investigate how teachers' beliefs and attitudes affect their intention and actual use of LMS. This study further verified the validity of the model to explain the users' technology acceptance behavior.

Future studies should highlight additional external factors that could explain the acceptance and usage of various teaching and learning technologies [28]. Similarly, Al-Maroof and Al-Meran [15] recommended that further extensions be made to determine the acceptance of Google Classroom as an LMS. Likewise, this can be done by deciding other factors that may influence its users' acceptance. In this study, online learning self-efficacy is used as an external variable that could affect user acceptance on Google Classroom. Online learning self-efficacy refers to how well an individual can perform the actions to meet challenges and complete tasks effectively in the online environment [29], [30]. Panergayo and Mansujeto [31] and Shen et al. [32] argued that is an essential factor to a successful online learning program. Self-efficacy to online learning is not limited to students' self-efficacy to learn in an online environment but also encompasses effective time management, and technology use [29]-[31]. Zimmerman \& Kulikowich [30] proposed three domains of online learning self-efficacy, which are learning in an online environment, technology use, and time management. These three factors emerged from the factor analysis during the development of the online learning self-efficacy scale.

\section{RESEARCH QUESTIONS}

This study investigates the mediating role of perceived usefulness and ease of use on the effect of students' online learning self-efficacy on their behavioral intention to use the learning management system. Specifically, it seeks to answer the following questions:

1) Do online learning self-efficacy factors, perceived usefulness, and perceived ease of use significantly predict students' behavioral intention to use the learning management system?

2) Do the perceived usefulness and ease of use significantly mediate online learning self-efficacy factors to students' behavioral intention to use learning management systems?

\section{Methodology}

\section{A. Research Design}

This study employed a cross-sectional explanatory research design. The researchers gathered information about the online learning self-efficacy, PU, PEOU, and BIU learning management system without manipulating these variables. Based on the collected data, the researchers established a link between online learning self-efficacy and behavioral intention to use learning management systems as mediated by PU and PEOU. The LMS considered in the study is Google Classroom. This LMS is institutionalized by the university, the research locale, to be the official teaching and learning platform for flexible learning modalities such as online learning delivery. 


\section{B. Respondents}

The primary respondents of this study are senior high school students from one state university in Laguna, Philippines. The researchers utilized the purposive non-probability sampling method to acquire the respondents. A total of 470 usable responses were collected from the target population. These data accounted for a $95.53 \%$ response rate from the participants' total population in the research site. The respondents are composed of $65.3 \%$ female and $34.7 \%$ male. The respondents' age ranges from 15 to 20 where the mean age is 17.23 years. The majority of the respondents have ages of $17(43.8 \%)$ and $18(35.7 \%)$. The respondents are senior high undergraduate students with $41.5 \%$ from Grade 11 and $58.5 \%$ from Grade 12. Different academic tracks were fairly represented as revealed by the number of the respondent - HUMSS (27\%), ABM (25.7\%), STEM (23.6\%), and TVL $(23.6 \%)$ tracks. Table I detailed the characteristics of the respondents.

TABLE I: CHARACTERISTICS OF THE RESPONDENTS

\begin{tabular}{|c|c|c|c|}
\hline & Demographics & $\mathbf{f}$ & $\%$ \\
\hline \multirow[t]{2}{*}{ Sex } & Female & 307 & 65.3 \\
\hline & Male & 163 & 34.7 \\
\hline \multirow[t]{6}{*}{ Age } & 15 & 1 & 0.2 \\
\hline & 16 & 84 & 17.9 \\
\hline & 17 & 206 & 43.8 \\
\hline & 18 & 168 & 35.7 \\
\hline & 19 & 7 & 1.5 \\
\hline & 20 & 4 & 0.9 \\
\hline \multirow{2}{*}{ Grade Level } & Grade 11 & 195 & 41.5 \\
\hline & Grade 12 & 275 & 58.5 \\
\hline \multirow{6}{*}{$\begin{array}{l}\text { Academic } \\
\text { Track }\end{array}$} & Accountancy, Business and & 121 & 25.7 \\
\hline & Managements (ABM) & & \\
\hline & $\begin{array}{l}\text { Humanities and Social Science } \\
\text { (HUMSS) }\end{array}$ & 127 & 27.0 \\
\hline & $\begin{array}{l}\text { Science, Technology, } \\
\text { Engineering, and Mathematics } \\
\text { (STEM) }\end{array}$ & 111 & 23.6 \\
\hline & $\begin{array}{l}\text { Technical Vocational Livelihood } \\
\text { (TVL) }\end{array}$ & 111 & 23.6 \\
\hline & TOTAL & 470 & 100 \\
\hline
\end{tabular}

\section{Instrument}

The instrument utilized in this study is adapted from the previous studies conducted by Zimmerman and Kulikowich (2016) and Al-Maroof and Al-Meran (2018). The researchers asked permission from the authors to use the selected items from their instruments for the study. The developed instrument was composed of three parts. The first section collects the respondents' demographic profile regarding sex, age, grade level, and academic track. Likewise, the second section measures the respondents' online learning self-efficacy in learning in an online environment, technology use, and time management. Lastly, the third section determines the students' behavioral intention to use the LMS and its PU and PEOU.

The instrument was content-validated by experts in educational technology, research and statistics, and measurement and evaluation. The instruments subscales obtained Cronbach's alphas ranging from 0.758 to 0.848 , indicating good internal consistency.

\section{Data Collection}

The data collection was conducted via an online survey encoded in a web-based program. The survey link was sent to the target sample via private and group messages posted on their Google Classroom. The senior high school department faculty assisted in distributing the survey and ensured that high retrieval of responses was attained. Proper research ethics measures and protocols were strictly observed by providing an informed consent form to the respondents signifying their understanding of the study's purposes. The document states that the confidentiality and anonymity of their response will be highly considered. Sensitive information about the respondents, such as names and email addresses, is only accessible to the researchers who will analyze it.

\section{E. Data Analysis}

This study used descriptive statistics such as mean and standard deviation to describe the respondents' perception regarding their online learning self-efficacy, PU, PEOU, and BIU learning management system. Pearson correlation coefficient $r$ was used to determine whether the study variables were significantly associated with each other. Lastly, separate mediation analyses following the procedure of Hayes [33] using PROCESS v3.5 were initiated to explore the mediating role of PU and PEOU in online learning self-efficacy on behavioral intention to use a learning management system.

\section{RESUlts}

This study reported the mean and standard deviation for the online learning self-efficacy in terms of 1) learning in an online environment; 2) technology use; and 3) time management, PU, PEOU, and BIU to use learning management system. It also determined the association among the subdomains of online learning self-efficacy and other study variables. It further explored the mediating role of PU and PEOU in influencing online learning self-efficacy to behavioral intention to use LMS.

Table II revealed that all online learning self-efficacy factors obtained relatively higher mean values, with technology use $(M=3.72, S D=0.57)$ attaining the highest mean and variability. Likewise, the result indicates that the student's beliefs about their capability in online learning are commendable. The PU $(M=3.58, S D=0.57)$ and PEOU $(M=4.07, S D=0.61)$ of the LMS both obtained high mean values indicating student's favorable acceptance in terms of the usability and comfortability of the LMS. Furthermore, students' behavioral intention $(M=3.67, S D=0.75)$ to use the learning management system registered a fair mean value. It demonstrates that students display positive attitudes towards using the LMS in the future. The instrument subscales obtained Cronbach's alphas ranging from 0.758 to 0.848 , which is an indicator of good scale internal consistency.

All the study variables in Table II established a strong and positive significant relationship, as revealed by coefficient $r$ tested at a 95\% confidence interval. Evans (1996) contended that coefficient $r$ ranging from 0.60 to .79 is interpreted as a strong correlation. Among the three factors of online learning self-efficacy, learning in the online environment registered 
the strongest correlation to PU $(r=0.688, p<0.01)$, to PEOU $(r=0.688, p<0.01)$, and to BIU $(r=0.657, p<0.01)$. It shows that the student's overall perspective towards learning in an online environment is directly linked to the learning platform used to implement online instruction. The weakest association, although still significant, registered between self-efficacy in time management and PEOU with a coefficient $r$ of 0.570 . It can be assumed that the ease of using an LMS is associated with how students will manage their time to become efficient and effective users.

Table III presents the coefficients of direct effects of the independent variables (factors of online learning self-efficacy) and mediators (PU and PEOU) to the outcome variable (behavioral intention to use). Regression analysis revealed that all online learning self-efficacy factors significantly predict the PU, PEOU, and BIU at a $95 \%$ confidence interval. The strongest predictor of $\mathrm{PU}(\beta=0.6841$, $p=0.000)$ and $\operatorname{BIU}(\beta=0.3392, p=0.000)$ is self-efficacy in learning in an online environment. It shows that a one-unit change in self-efficacy in learning in an online environment can result in a .6841-unit change in the perceived usefulness and a .3392-unit change in behavioral intention to use. The self-efficacy in technology use $(\beta=0.7325, \quad p=0.000)$ registered to be the most vital determinant of PEOU. It follows that one-unit change in self-efficacy in technology use can predict a .7325-unit change in the PEOU.

Furthermore, $\mathrm{PU}(\beta=0.4321, p=0.000)$ and perceived ease of use $(\beta=0.3166, p=0.000)$ positively influence the students' BIU learning management system, as shown by their path coefficients. The result assumes in all cases that all other predictors are held constant. The table further indicates that an estimated $55 \%$ of the students' BIU learning management system's variation, as revealed by the $\mathrm{R} 2$ values, can use one unit by online learning self-efficacy, PU, and PEOU of the LMS.

TABLE II: MEAN, StANDARD DEVIATION, CRONBACH'S AlPHA, AND CORRELATIONS AMONG THE STUDY VARIABLES

\begin{tabular}{|c|c|c|c|c|c|c|}
\hline Variables & 1 & $\overline{2}$ & 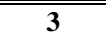 & 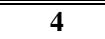 & 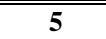 & 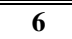 \\
\hline $\begin{array}{l}\text { 1. Learning in an Online } \\
\text { Environment (LOE) }\end{array}$ & -- & & & & & \\
\hline 2. Technology Use (TU) & $0.782 * *$ & -- & & & & \\
\hline 3. Time Management (TM) & $0.752 * *$ & $0.610 * *$ & -- & & & \\
\hline 4. Perceived Usefulness (PU) & $0.688 * *$ & $0.641 * *$ & $0.640 * *$ & -- & & \\
\hline 5. Perceived Ease of Use (PEOU) & $0.688 * *$ & $0.682 * *$ & $0.570^{* * *}$ & $0.659 * *$ & -- & \\
\hline 6. Behavioral Intention to Use (BIU) & $0.657 * *$ & 0.614 & $0.608 * *$ & $0.676 * *$ & $0.646^{* * *}$ & -- \\
\hline Mean & 3.63 & 3.72 & 3.64 & 3.58 & 4.07 & 3.67 \\
\hline$S D$ & 0.58 & 0.57 & 0.70 & 0.57 & 0.61 & 0.75 \\
\hline Cronbach's Alpha & 0.848 & 0.824 & 0.833 & 0.758 & 0.835 & 0.813 \\
\hline
\end{tabular}

TABLE III: REGRESSION COEFFICIENTS, STANDARD ERRORS, AND MODEL SUMMARY FOR THE PRESUMED INFLUENCE OF ONLINE LEARNING SELF-EFFICACY FACTORS TO BEHAVIORAL INTENTION TO USE LMS

\begin{tabular}{|c|c|c|c|c|c|c|c|c|c|}
\hline \multirow[b]{3}{*}{ Antecedent } & \multicolumn{9}{|c|}{ Consequent } \\
\hline & \multicolumn{3}{|c|}{ Perceived Usefulness (PU) } & \multicolumn{3}{|c|}{ Perceived Ease of Use (PEOU) } & \multicolumn{3}{|c|}{ Behavioral Intention to Use (BIU) } \\
\hline & $\beta$ & $S E$ & $p$ & $\beta$ & $S E$ & $p$ & $\beta$ & $S E$ & $p$ \\
\hline Constant & 1.098 & 0.123 & 0.000 & 1.520 & 0.133 & 0.000 & -0.404 & 0.171 & 0.0186 \\
\hline $\begin{array}{l}\text { Learning in an Online } \\
\text { Environment (LOE) }\end{array}$ & 0.684 & 0.033 & 0.000 & 0.705 & 0.036 & 0.000 & 0.339 & 0.060 & 0.000 \\
\hline $\begin{array}{l}\text { Perceived Usefulness } \\
\text { (PU) }\end{array}$ & -- & -- & -- & -- & -- & -- & 0.432 & 0.060 & 0.000 \\
\hline \multirow[t]{2}{*}{$\begin{array}{l}\text { Perceived Ease of Use } \\
\text { (PEOU) }\end{array}$} & -- & -- & -- & -- & -- & -- & 0.317 & 0.055 & 0.000 \\
\hline & \multicolumn{3}{|c|}{$\begin{array}{c}R^{2}=0.473, \\
F=420.552, p=0.000\end{array}$} & \multicolumn{3}{|c|}{$\begin{array}{c}R^{2}=0.446, \\
F=376.60 p=0.000\end{array}$} & \multicolumn{3}{|c|}{$\begin{array}{c}R^{2}=0.558 \\
F=195.45, p=0.000\end{array}$} \\
\hline Constant & 1.170 & 0.135 & 0.000 & 1.352 & 0.137 & 0.000 & -0.403 & 0.176 & 0.023 \\
\hline \multirow{3}{*}{$\begin{array}{l}\text { Technology Use (TU) } \\
\text { Perceived Usefulness } \\
\text { (PU) } \\
\text { Perceived Ease of Use } \\
\text { (PEOU) }\end{array}$} & 0.648 & 0.036 & 0.000 & 0.733 & 0.036 & 0.000 & 0.252 & 0.061 & 0.000 \\
\hline & -- & -- & -- & -- & -- & -- & 0.331 & 0.058 & 0.000 \\
\hline & \multicolumn{3}{|c|}{$\begin{array}{c}R^{2}=0.410, \\
F=324.857, p=0.000\end{array}$} & \multicolumn{3}{|c|}{$\begin{array}{c}R^{2}=0.466, \\
F=406.817, p=0.000\end{array}$} & \multicolumn{3}{|c|}{$\begin{array}{c}R^{2}=0.545, \\
F=185.389, p=0.000\end{array}$} \\
\hline Constant & 1.688 & 0.107 & 0.000 & 2.290 & 0.1216 & 0.000 & -0.288 & 0.169 & 0.088 \\
\hline Time Management (TM) & 0.520 & 0.029 & 0.000 & 0.492 & 0.033 & 0.000 & 0.239 & 0.044 & 0.000 \\
\hline $\begin{array}{l}\text { Perceived Usefulness } \\
(\mathrm{PU})\end{array}$ & -- & -- & -- & -- & -- & -- & 0.444 & 0.060 & 0.000 \\
\hline \multirow[t]{2}{*}{$\begin{array}{l}\text { Perceived Ease of Use } \\
(\mathrm{PEOU})\end{array}$} & -- & -- & -- & -- & -- & -- & 0.366 & 0.053 & 0.000 \\
\hline & \multicolumn{3}{|c|}{$\begin{array}{c}R^{2}=0.6399, \\
F=323.822, p=0.000\end{array}$} & \multicolumn{3}{|c|}{$\begin{array}{c}R^{2}=0.3245, \\
F=224.298, p=0.000\end{array}$} & \multicolumn{3}{|c|}{$\begin{array}{c}R^{2}=0.555, \\
F=193.596, p=0.000\end{array}$} \\
\hline
\end{tabular}




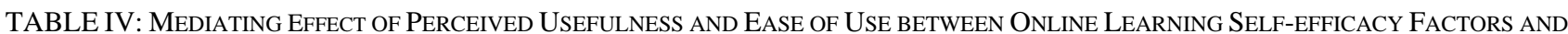
STUDENTS' BEHAVIORAL INTENTION TO USE LMS

\begin{tabular}{lcccc}
\hline \hline \multicolumn{1}{c}{ Indirect Effects } & Effect & SE & LLCI & ULCI \\
\hline $\mathrm{LOE} \rightarrow \mathrm{PU} \rightarrow \mathrm{BIU}$ & 0.2956 & 0.0520 & 0.1934 & 0.3996 \\
$\mathrm{LOE} \rightarrow \mathrm{PEOU} \rightarrow$ BIU & 0.2231 & 0.0494 & 0.1276 & 0.3217 \\
$\mathrm{TU} \rightarrow \mathrm{PU} \rightarrow \mathrm{BIU}$ & 0.3225 & 0.0538 & 0.2210 & 0.4320 \\
$\mathrm{TU} \rightarrow \mathrm{PEOU} \rightarrow$ BIU & 0.2421 & 0.0504 & 0.1453 & 0.3427 \\
$\mathrm{TM} \rightarrow \mathrm{PU} \rightarrow \mathrm{BIU}$ & 0.2312 & 0.0407 & 0.1527 & 0.3135 \\
$\mathrm{TM} \rightarrow \mathrm{PEOU} \rightarrow \mathrm{BIU}$ & 0.1800 & 0.0334 & 0.1146 & 0.2454 \\
\hline \hline
\end{tabular}

Table IV displays the mediating role of PU and PEOU on the effect of three factors of online learning self-efficacy on students' BIU learning management system. It shows that PU and PEOU significantly mediate online learning self-efficacy to students' BIU learning management system. These indirect effects are statistically different from zero, as revealed by a biased-corrected bootstrap confidence interval based on 10,000 samples from the lower and upper limit class interval. The result indicates that perceived usefulness and ease of use can transmit the effect of influenced by online learning self-efficacy, which increases the behavioral intention to use. It can also be noticed that the PU demonstrated the highest mediating effect of .3225 . This indirect effect means that respondents who differ by one unit in their reported self-efficacy to technology use are estimated to vary by .3225 units on their intended use of the LMS. The results from those who have relatively higher self-efficacy in technology use, realizing the system's usefulness later translate into greater intention to use the LMS.

\section{DISCUSSION}

\section{A. Direct Effects of Online Learning Self-efficacy Factors, Perceived Usefulness and Ease of Use to Students' Behavioral Intention to Use LMS}

This study showed that all the factors of online learning self-efficacy such as learning in an online environment, time management, and technology use, emerged to influence the students' BIU significantly. This clearly shows that the students' self-confidence in learning in the online environment can explain their continuous behavioral intention to use LMS. The existing literature supports this finding of self-efficacy in online learning. For instance, Broadbent [34] established the central role of self-efficacy in determining students' performance. The study revealed that self-efficacy is an important factor compared to the experience in using LMS suggesting that self-beliefs account for learning analytics and frequent use of LMS, which in turn increases students' academic performance. In the study of Landrum [35], the results revealed that confidence to use online learning platforms is the strongest predictor of satisfaction and perceived usefulness of online classes. It indicates that those students who reported greater confidence in navigation online learning results in greater satisfaction in using LMS.

The findings further uncovered that PU and PEOU are both significant predictors of students' BIU. It suggests that the students' perceptions regarding the usefulness and ease of using the LMS can explain their future intention and continue to use LMS. This finding is consistent with the results of previous studies, which revealed a strong predictive relationship between PU, PEOU, and attitudes towards the use of LMS, which affects intention to use [11], [17], [27], [36], [37]. The study conducted by Al-Maroof and Al-Emran [15] also proved that PU and PEOU positively impact the BIU, which eventually influences the actual LMS usage. The results imply that the student's perception regarding the usefulness and manageability of the LMS can enhance the students' intent to utilize and continue using LMS. Thus, teachers and school administrators should consider the usability and user-friendliness features of LMS to continue implementing LMS-based courses in the future.

\section{B. Mediating Effect of Perceived Usefulness and Ease of Use between Online Learning Self-Efficacy Factors and Behavioral Intention to Use LMS}

The present study found out that PU and PEOU emerged to have mediating roles in the relationship between online learning self-efficacy and students' BIU. This suggests that the students who reported higher online learning self-efficacy in learning in a virtual environment, using technology, and managing time professed the usefulness and ease of using LMS to a greater extent, which eventually translated to increased intention to continue using LMS in the future. This finding is supported by the study conducted by Ansong-Gyimah [36] where he examined the perceptions and continuous intention to use e-learning system and revealed that attitude towards use is positively influenced by PU and PEOU, transmitting the effect to continued intent to use LMS. Chirchir et al. [37] further provided evidence about the mediating role of PU and PEOU to user performance. Their study revealed that performance outcomes increased when the individual users perceived the information system to be useful and easy to use.

Similarly, Lao et al. [38] investigated the mediating role of PU and PEOU between computer self-efficacy and willingness to use web-based assessment systems. Path analysis revealed that PU and PEOU mediate the influence of self-efficacy on user's willingness. This indicates that students with a higher perception of the usefulness and ease of use of the technology will, in turn, increase their willingness to use the said system. Dumpit and Fernandez [39] also illustrated the PU and PEOU as robust predictors of usage behavior of students along with subjective norms and happiness. It further shows that continuous use of a specific system should be encouraged because the intention to use translates to the actual use of the system.

Huynh and Thi [40] contended that the mediating role of the perception on PU in the relationship between perceived ease of use and the acceptance of e-learning is a crucial 
element. Arunachalam [41] also explored the role of PU, PEOU, and self-efficacy in determining the continuous usage of an e-learning system. The results uncovered that PU and BIU, PEOU and BIU and self-efficacy and BIU are all facilitated by e-learner satisfaction. This indicates that e-learner satisfaction should be reinforced if the continuous usage intention is to be improved. It is no doubt that performance outcomes become higher when individual users' perceptions of the information system consider it valuable and easy to use. This study confirmed the original Technology Acceptance Model set forth by Davies in 1989. Davies (1989) claimed in his model that PU and PEOU could mediate the effect of an identified external variable on the students' behavioral intention to use a particular technology or information system. Fathema et al. [17] modified the original TAM but still identified PU and PEOU as mediating variables. The extended model proposed by Fathema et al. [17] also supported the results of the study. The model suggests that perceived self-efficacy significantly influences both PU and PEOU, which affects the attitudes towards use which further translates to intention to use the system. This explains why intended users who are confident about their LMS skills perceive LMS as a useful system to use and experience fewer difficulties.

\section{LIMITATIONS}

The present study only involved one state university in the Philippines, particularly the senior high school department. The senior high school students experienced using a LMS (Google Classroom) for one semester, which is approximately five months. This study was conducted using a cross-sectional explanatory research design; thus, the data were collected only in a specified time and single method. The study also used a self-report questionnaire where responses can be influenced by the respondents' emotional and physical well-being when they answered the survey. Furthermore, this study only considered online learning self-efficacy factors as the external variable that may affect the PU, PEOU, and BIU. This variable is regarded as a student-related factor which means that other external variables such as teacher- and environment-related factors were not measured. The result can shed more light regarding the extent of students' BIU learning management system in the future to support flexible delivery of teaching and learning.

\section{CONCLUSIONS AND IMPLICATIONS}

The main objective of this study was to establish the mediating role of perceived usefulness and perceived ease of use on the relationship between online learning self-efficacy factors (LOE, TM, and TU) and the students' behavioral intention to use an LMS in one state university in the Philippines. The study produced results consistent with previous studies, which states that the future purpose of using information systems such as LMS is best enhanced when the system is more valuable and easier to use. Based on the research questions proposed and salient findings of this study, the following conclusions were drawn. The students' behavioral intention to use the LMS is influenced by their online learning self-efficacy in learning in an online environment, time management, and technology use. It is also found out that the student's perception of the usefulness and ease of use of LMS can explain their future intention to use learning management system. Furthermore, perceived effectiveness and ease of use emerged to mediate online learning self-efficacy factors and behavioral intention to use. The result implies that students with a good level of self-efficacy in online learning perceived LMS as useful and easy to use, which translates to a greater extent of using LMS in the future. To increase the behavioral intention to use LMS of the students, teachers need to augment the students' perception about the LMS in terms of usability and ease of use towards the system in teaching and learning. In essence, students would continue using LMS as soon as they found the system both helpful and easy to use. To uplift their perceptions regarding the use of LMS, their self-efficacy in online learning should be examined since the current study revealed that online learning self-efficacy has a positive effect on PU and PEOU. The school and the teachers must organize educational activities emphasizing the development of self-efficacy towards online learning. This includes but is not limited to activities utilizing the technical know-how of the LMS.

These findings have significant implications for the successful implementation of LMS-based courses in the context of upper secondary level. First, the study results could provide salient inputs in the development and adoption of LMS to support flexible learning delivery methods such as online and blended learning modalities. Second, the study highlighted the mediating role of perceived usefulness and ease of use towards LMS acceptance. Likewise, it could inform educational policymakers to explore the merits of LMS in terms of its usefulness and manageability to increase students' intention to utilize LMS further in their learning journey. Third, this study suggests that students' future purpose of using LMS can be explained by various factors such as online learning self-efficacy, perceived usefulness, and ease of use. It highlights the contributing factor that must be considered to effectively apply LMS at the senior high school level. Fourth, this study further suggests that self-confidence in online learning, such as online learning self-efficacy to use technology and manage time effectively, are essential elements of actual use and acceptance. Finally, for future research directions, succeeding studies may ascertain other external factors that can determine the perceived usefulness and ease of use, affecting the student's future intention to use LMS.

\section{CONFLICT OF INTEREST}

The authors declare no conflict of interest in this research undertaking.

\section{AUTHOR CONTRIBUTIONS}

AAEP conceptualized the research topic, analyzed and interpreted the data, wrote the paper; JVCA collected, analyzed, and interpreted the data, edited the technical format. 
Both authors had approved the final version.

\section{ACKNOWLEDGMENT}

The authors would like to express their sincerest gratitude to the Laguna State Polytechnic University for supporting this research endeavor. Likewise, the same appreciation is extended to the Senior High School Department of allowing the conduct of this study in their locale.

\section{REFERENCES}

[1] E. Dahlstrom, D. C. Brooks, and J. Bichsel, "The current ecosystem of learning management systems in education: Student, faculty, and IT perspectives," Research Report, Louisville, CO: ECAR, 2014.

[2] D. Ifenthaler, "Learning management system," Encyclopedia of the Sciences of Learning, Springer, Boston, MA, 2021.

[3] R. Watson and S. Watson, "An argument for clarity: What are learning management systems, what are they not, \& what should they become?" TechTrends, vol. 51, no. 2, pp. 28-34, 2007.

[4] A. Anshari, M. N. Almunawar, M. Shahrill, D. K. Wicaksono, and M. Huda, "Smartphones usage in the classrooms: Learning aid or interference?" Education and Information Technologies, vol. 22 no. 6 , pp. 3063-3079, 2017.

[5] V. M. Bradley, "Learning management system (LMS) use with online instruction," International Journal of Technology in Education (IJTE), vol. 4, no. 1, pp. 68-92, 2021.

[6] J. Rhode, S. Richter, P. Gowen, T. Miller, and C. Wills, "Understanding faculty use of the learning management system," Online Learning, vol. 21, no. 3, pp. 68-86, 2017.

[7] Y. Vovides, S. Sanchez-Alonso, V. Mitropoulou, and G. Nickmans, "The use of e-learning course management systems to support learning strategies and to improve self-regulated learning," Educational Research Review, vol. 2, no. 1, pp. 64-74, 2007.

[8] D. Turnbull, R. Chugh, and J. Luck, "Learning management systems: An overview," Encyclopedia of Education and Information Technologies, Springer, Cham, 2019.

[9] Y. Ghilay, "Effectiveness of learning management systems in higher education: Views of lecturers with different levels of activity in LMSs," Journal of Online Higher Education, vol. 3, no. 2, pp. 29-50, 2019.

[10] L. Y. Chaw and C. M. Tang, "What makes learning management systems effective for learning?" Journal of Educational Technology Systems, vol. 47, no. 2, pp. 152-169, 2018.

[11] M. R. Fearnley and J. T. Amora, "Learning management system adoption in higher education using the extended technology acceptance model," IAFOR Journal of Education, Technology in Education, vol. 8, no. 2, pp. 89-106, 2020.

[12] P. Jakkaew and S. Hemrungrote, "The use of UTAUT2 model for understanding student perceptions using Google Classroom: A case study of introduction to information technology course," in Proc. 2017 International Conference on Digital Arts, Media and Technology (ICDAMT), pp. 205-209, 2017.

[13] A. Revythi and N. Teslios, "Extension of technology acceptance model by using system usability scale to assess behavioral intention to use e-learning," Education and Information Technologies, vol. 24, no. 4, pp. 2342-2355, 2019.

[14] N. Dulkaman and A. M. Ali, "Factors influencing the success of learning management system (LMS) on students' academic performance," IYSJL, vol. 1, no. 1, pp. 36-49, 2016.

[15] R. A. S. Al-Maroof and M. Al-Emran, "Students' acceptance of Google Classroom: An exploratory study using PLS-SEM approach," International Journal of Emerging Technologies in Learning, vol. 13, no. 6, pp. 112-123, 2018.

[16] S. Dash, "Google classroom as a learning management system to teach biochemistry in a medical school," Biochem Mol Biol Education, vol. 47, no. 4, pp. 404-407, 2019.

[17] N. Fathema, D. Shannon, and M. Ross, "Expanding the technology acceptance model (TAM) to examine faculty use of learning management systems (LMSs) in higher education institutions," MERLOT Journal of Online Learning and Teaching, vol. 11, no. 2, pp. 210-232, 2015

[18] T. Farahat, "Applying the technology acceptance model to online learning in the Egyptian universities," Procedia - Social and Behavioral Sciences, vol. 64, pp. 95-104, 2012.
[19] M. B. Garcia, "E-learning technology adoption in the Philippines: An investigation of factors affecting Filipino college students' acceptance of learning management systems," The International Journal of e-Learning and Educational Technologies in the Digital Media, vol. 3, no. 3, pp. 118-130, 2015.

[20] K. A. Azhar and N. Iqbal, "Effectivenes of Google classroom: Teachers' perception," Prizren Social Science Journal, vol. 2, no. 2, pp. 52-66.

[21] F. D. Davis, "Perceived usefulness, perceived ease of use, and user acceptance of information technology," MIS Quarterly, vol. 13, no. 3, pp. 319-340, 1989.

[22] R. J. Holden and B. T. Karsh, "The technology acceptance model: Its past and its future in health care," Journal of Biomedical Informatics, vol. 43, pp. 159-172, 2009.

[23] P. Surendran, "Technology acceptance model: A survey of literature," International Journal of Business and Social Research, vol. 2, no. 4, 175-178. 2012.

[24] V. Venkatesh, "Determinants of perceived ease of use: Integrating control, intrinsic motivation, and emotion into the technology acceptance model," Information Systems Research, vol. 11, pp. 342-365, 2000.

[25] Y. Wu and C. Tsai, "University Students' Internet attitudes and internet self-efficacy: A study at three universities in Taiwan," Cyber Psychology \& Behavior, vol. 9, no. 4, pp. 441-450, 2006.

[26] L. Benbasat and H. Barki, "Quo vadis TAM?" Journal of the Association for Information Systems, vol. 8, no. 4, pp. 211-218, 2007.

[27] A. Stockless, "Acceptance of learning management system: The case of secondary school teachers," Education and Information Technologies, vol. 23, no. 3, pp. 1101-1121, 2018.

[28] A. Granic and N. Marangunic, "Technology acceptance model in educational context: A systematic literature review," British Journal of Educational Technology, vol. 0, no. 0, pp. 1-22, 2019

[29] E. Z. Andal, A. A. E. Panergayo, and M. R. G. Almanza, "Exploring the online learning self-efficacy of teacher education students in Laguna State Polytechnic University: Basis for transition to flexible learning system," Universal Journal of Educational Research, vol. 8, no. 12, pp. 6598-6608, 2020.

[30] W. A. Zimmerman and J. M. Kulikowich, "Online learning self-efficacy in students with and without online learning experience," American Journal of Distance Education, vol. 30, no. 3, pp. 180-191, 2016.

[31] A. A. E. Panergayo and K. A. Mansujeto, "Assessment of self-efficacy in an online learning of teacher education students in one state university in the Philippines," International Journal of Computing Sciences Research, vol. 5, no. 1.

[32] D. Shen, M. Cho, C. Tsai, and R. Marra, "Unpacking online learning experience: Online learning self-efficacy and learning satisfaction," The Internet and Higher Education, vol. 19, pp. 1-17, 2013.

[33] A. F. Hayes, Introduction to Mediation, Moderation, and Conditional Process Analysis: A Regression-based Approach, The Guilford Press, 2013.

[34] J. Broadbent, "Academic success is about self-efficacy rather than frequency of use of the learning management system," Australasian Journal of Educational Technology, vol. 32, no. 4, pp. 38-49, 2016.

[35] B. Landrum, "Examining students' confidence to learn online, self-regulation skills and perceptions of satisfaction and usefulness of online classes," Online Learning, vol. 24, no. 3, pp. 128- 146, 2020.

[36] K. Ansong-Gyimah, "Students' perceptions and continuous intention to use e-learning systems: The case of Google Classroom," International Journal of Emerging Technologies In Learning (IJET), vol. 15, no. 11, pp. 236-244, 2020

[37] L. K. Chirchir, W. K. Aruasa, and S. K. Chebon, "Perceived usefulness and ease of use as mediators of the effect of health information systems on user performance," European Journal of Computer Science and Information Technology, vol. 7, no. 1, pp. 22-37, 2019.

[38] S. Liao, J. Hong, M. Wen, Y. Pan, and Y. Wu, "Applying technology acceptance model (TAM) to explore users' behavioral intention to adopt a performance assessment system for e-book production," EURASIA Journal of Mathematics, Science and Technology Education, vol. 14 , no. 10,2018

[39] D. Z. Dumpit and C. J. Fernandez, "Analysis of the use of social media in higher education institutions (HEIs) using the technology acceptance model," International Journal of Educational Technology in Higher Education, vol. 14, 5, 2017.

[40] Q. L. Huynh and T. L. L. Thi, "The mediating role of perceived usefulness and ease of use," International Journal of Humanities and Social Science Invention, vol. 3, no. 2, pp. 37-42, 2014. 
[41] T. Arunachalam, "An investigation on the role of perceived ease of use, perceived use and self-efficacy in determining continuous usage intention towards an e-learning system," The Online Journal of Distance Education and e-Learning, vol. 7, no. 4, pp. 268-276.

Copyright $(2021$ by the authors. This is an open access article distributed under the Creative Commons Attribution License which permits unrestricted use, distribution, and reproduction in any medium, provided the original work is properly cited (CC BY 4.0).

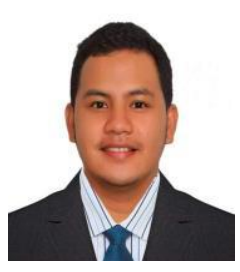

Albert Andry E. Panergayo was born in San Pablo city, Laguna. Philippines, famously known as City of Seven Lakes, in August 18, 1996. He graduated with the degree of bachelor in secondary education major in physical science from the Laguna State Polytechnic University, San Pablo City Campus as magna cum laude. He further graduated from Philippine Normal University - Taft, Manila, the country's National Center for Teacher Education, obtaining the degree of master of arts in science education with specialization in physics under the capacity building program for science and mathematics educators. He is currently affiliated to Laguna State Polytechnic University teacher courses related to Physic and professional courses such as educational technology for science pre-service teachers. His research interests include technology integration to education, pedagogical practices in Physics, and creativity in science education.

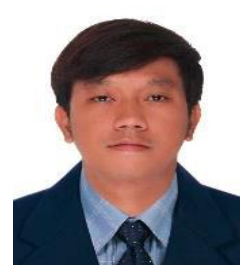

John Vincent C. Aliazas was born in San Pablo City, Laguna. Philippines in 1987. He received his Master of Arts in Science and Technology from Laguna State Polytechnic University, San Pablo City in 2014. He is currently pursuing Doctor of Philosophy in Science Education in Philippine Normal University - Taft, Manila. He has been working in the College of Teacher Education at Laguna State Polytechnic University - San Pablo City Campus since June 2012. He is presently serving in his capacity as the Chairperson for Senior High School Program at the said university. He handles professional subjects like technology for teaching and learning and science specialization courses for pre-service teachers. His research interests are the application of digital learning, technology for teaching and learning, and science education. 